\title{
A parametric study on the effects of surface explosions on buried high pressure gas pipelines
}

\author{
Omid Adibi, Amin Azadi, Bijan Farhanieh, Hossein Afshin*
}

Center of Excellence in Energy Conversion, School of Mechanical Engineering, Sharif University of Technology, Iran

\begin{tabular}{l}
\hline A R T I C L EI N F O \\
\hline Article history: \\
Received 6 June, 2017 \\
Accepted 11 September 2017 \\
Available online \\
11 September 2017 \\
\hline Keywords: \\
Surface Blasts \\
Natural Gas Pipelines \\
Numerical Methods \\
Fluid Solid Interaction \\
Safety
\end{tabular}

\section{Introduction}

\section{A B S T R A C T}

\begin{abstract}
Underground gas pipelines are one of the vital parts of each country which surface blasts can break down such pipelines, making destructive explosions and threatening the safety of neighborhood structures and people. In this paper, to enhance the safety of these lines, response of a buried 56-inch diameter high pressure natural gas pipeline to a surface blast was numerically investigated. Besides, the effects of: i) explosive mass, ii) pipeline thickness, iii) burial depth and iv) concrete protective layer on pipeline deformation were parametrically studied. To simulate the problem according to actual explosion events, geometries were modeled in real scales, pipeline properties were predicted with Johnson-Cook strength and failure model and soil strength was determined by Drucker-Prager model. Also, explosive charge and natural gas were modeled with JWL (Jones-Wilkins-Lee) and ideal gas equation of states. For validation of the numerical method, three bench mark experiments were reproduced. Comparison of the numerical results and the experimental data confirmed the accuracy of the numerical method. Results of parametric studies indicated that by increasing the burial depth from 1.4 to $2.2 \mathrm{~m}$, deformation of the pipeline was reduced about $71 \%$. By analyzing the deformation plots, it was found that in a constant explosive mass, burial depth has a greater effect than pipeline thickness on pipeline deformation reduction. It was also shown that using a concrete protective layer may act reversely and increase pipeline destruction. In other words, to enhance the safety of pipelines, a certain thickness of concrete must be used.
\end{abstract}

() 2017 Growing Science Ltd. All rights reserved.

Underground water, wastewater, oil and gas pipelines are among the main parts of each country which must resist against damaging effects of landslides, earthquakes and explosions. Blast waves that produce vibration in a wide variety of soil environment can be damaging for these pipelines. Therefore, in order to improve the safety of underground transmission pipelines, knowledge about dynamic impact of explosions and response of structures would be useful (Mokhtari \& Alavi Nia, 2015; Wilkening \& Baraldi, 2007). Explosion phenomenon has been an interesting field to researchers worldwide. In one

* Corresponding author. Tel: +98 (21) 6616 5530; Fax: +98 (21) 66000021

E-mail addresses: afshin@sharif.edu (H. Afshin) 
of the first studies in this regard, Gilbert and Kenneth (1985) precisely worked on governing equations and physics of produced shock waves from explosions. They also proposed an analytical relation for calculation of blast overpressure. In 1990, during a joint work of the Army, Air Force and Navy of the United State (Castellano et al. 1990), pressure waves created from explosion of $45.4 \mathrm{~kg}$ TNT were explored. The aim of this joint study was to determine the magnitude of overpressure caused by explosion in different periods of time. The results of this joint work are known as a benchmark experimental data on blast and used as a validation case in different studies (Baylot et al., 2005; Rickman \& Murrell, 2007; Son \& Lee, 2011).

After initial studies in the field of explosion, researchers have examined the effects of explosive charges on surrounding soil. Among these researches, studies that are conducted by Ambrosini's team (Ambrosini et al. 2004; Ambrosini \& Luccioni 2012; Ambrosini et al. 2002; Ambrosini \& Luccioni, 2006; Luccioni et al., 2009) are noticeable. This team has conducted analytical, experimental and numerical studies to determine the diameter of produced crater in the case of surface and subsurface explosions. Other similar studies were performed about the effects of explosions on different kinds of soils by Mambou et al. (2015) and Tarefder et al. (2016).

Because of the critical importance of explosion effects on surrounding structures, lots of researches have been conducted in this field (Alonso et al., 2008; Du et al., 2016; Li et al. 2014; Mirzaei et al. 2015; Trelat et al. 2007; Zhang et al. 2015). Trelat et al. (2007), Alonso et al. (2008) and Li et al. (2014) investigated the effects of explosives on neighborhood structures and buildings. Mirzaei et al. (2015) investigated structural waves of an explosive string situated in central line of a tube. Zhang et al. (2015) used a TNT equivalent method to analyze the dynamic responses of a spherical tank under external blasts. Du et al. (2016) proposed a coupled finite element method and smoothed particle hydrodynamics method to simulate the explosion processes inside pipelines. In recent years, terrorist attacks and use of surface explosions for destruction of underground structures have been increased. In this regard, lots of researches have been prepared to improve the safety of underground structures. Among these researches, studies of Koneshwaran et al. (2015), Yang et al. (2010) and Panji et al. (2016) can be noted, which have used numerical methods to investigate the effects of surface blast on underground tunnels. However, researches regarding the effects of surface explosions on underground pipelines have been neglected and little works have been done on this area (Jing et al. 2014; Mokhtari \& Alavi Nia, 2016; Mokhtari \& Alavi Nia, 2015). Due to complexity of the problem, in these researches, simplifying assumptions have been used. Jing et al. (2014) simulated the effects of surface blast on underground gas pipelines in a two dimensional model. Mokhtari and Alavi Nia (2016) studied application of a CFRP (Carbon Fiber Reinforced Polymer) layer to strengthen buried steel pipelines against subsurface explosion. The results of this study showed that a certain thickness of protective layer can guarantee the safety of underground pipelines against explosive loads.

Following the earlier numerical researches, in the present study, effects of surface explosions on buried natural gas transmission pipelines were simulated with actual assumptions. Hence, to enhance the accuracy of the results, dimensions were modeled in real scales, material behavior was predicted by high accurate material property models and strongly-coupled two-way methods were considered for fluid-structure interactions. In the second part of the paper, the numerical procedure to simulate the problem was presented in details and accuracy of numerical methods was evaluated. In the third part, effects of explosive mass charge, pipe thickness, burial depth and concrete protective layer on pipeline deformation were studied and effects of each item on damage reduction were compared. Finally, the remarkable results were summarized in the conclusion part.

\section{Materials and method}

\subsection{Problem description}

In this paper, to enhance the safety of high pressure gas pipelines, response of a buried 56-inch diameter pipe to a surface blast was investigated by finite element numerical methods. To simulate the problem according to actual explosion events, geometries were modeled in real scales, grids were 
generated with 8-node brick elements, boundaries and initial conditions were applied similar to real scenarios and material properties were predicted by high accurate state, resistance and failure models. In following paragraphs, the problem is explained in more details.

\section{Three dimensional model}

The pipe diameter and thickness were considered to be $1422 \mathrm{~mm}$ (56 inch) and $25 \mathrm{~mm}$, respectively. These standard values are used by international gas companies in the design of high pressure gas pipelines. For parametric study on effects of explosive mass charges, 150, 350, 650 and $900 \mathrm{~kg}$ TNT were considered in numerical models. In Fig. 1, longitudinal section and detailed dimensions of the simulated model were shown for $900 \mathrm{~kg}$ explosive charge in different views. In this figure, natural gas, air, soil, steel pipeline and explosive charge were shown with yellow, blue, brown, gray and red colors, respectively.
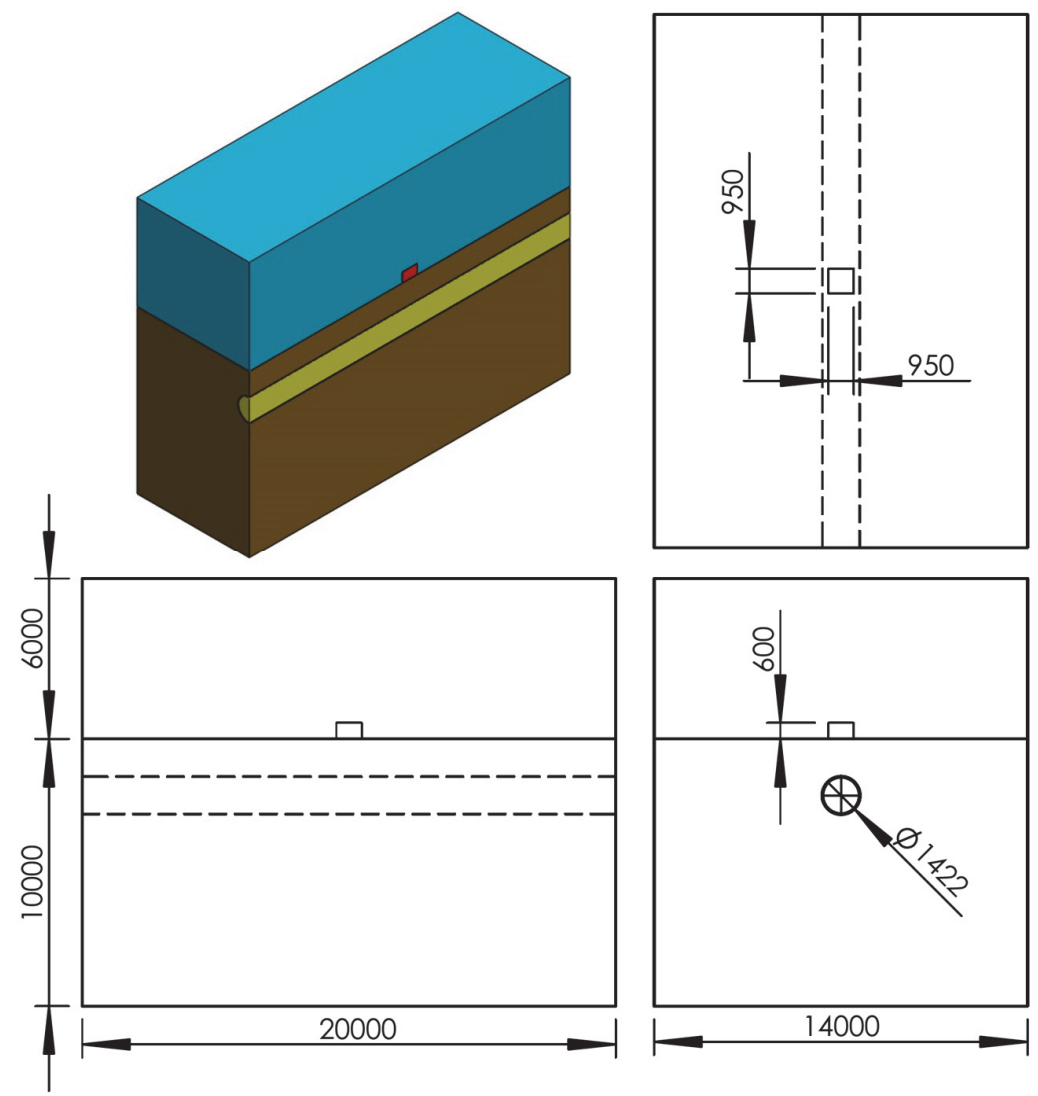

Fig. 1. Longitudinal section and detailed dimensions of the simulated model (dimensions are in $\mathrm{mm}$ )

\section{Grid generation}

In simulations, air, soil, natural gas and explosive charge were modeled with Eulerian grids and the governing equations were solved by the finite volume method. Also, the pipeline and concrete were modeled with Lagrangian grids and the governing equations were solved by the finite element method. Both Eulerian and Lagrangian domains were modeled with 8 node brick elements and the numbers of the grids were $3,481,600$ and 177,280, respectively. To enhance the accuracy of numerical solutions and due to the sharp gradients, finer grids (in order of $1 \mathrm{~cm}$ ) were used for the area near the pipeline and the soil between the explosive charge and pipeline. The grid sizes increased gradually in further parts and the maximum grid size was about $70 \mathrm{~cm}$. This issue is clearly illustrated in Fig. 2. In this figure, grids in the transversal section were presented and the area near the pipeline elements was magnified. 


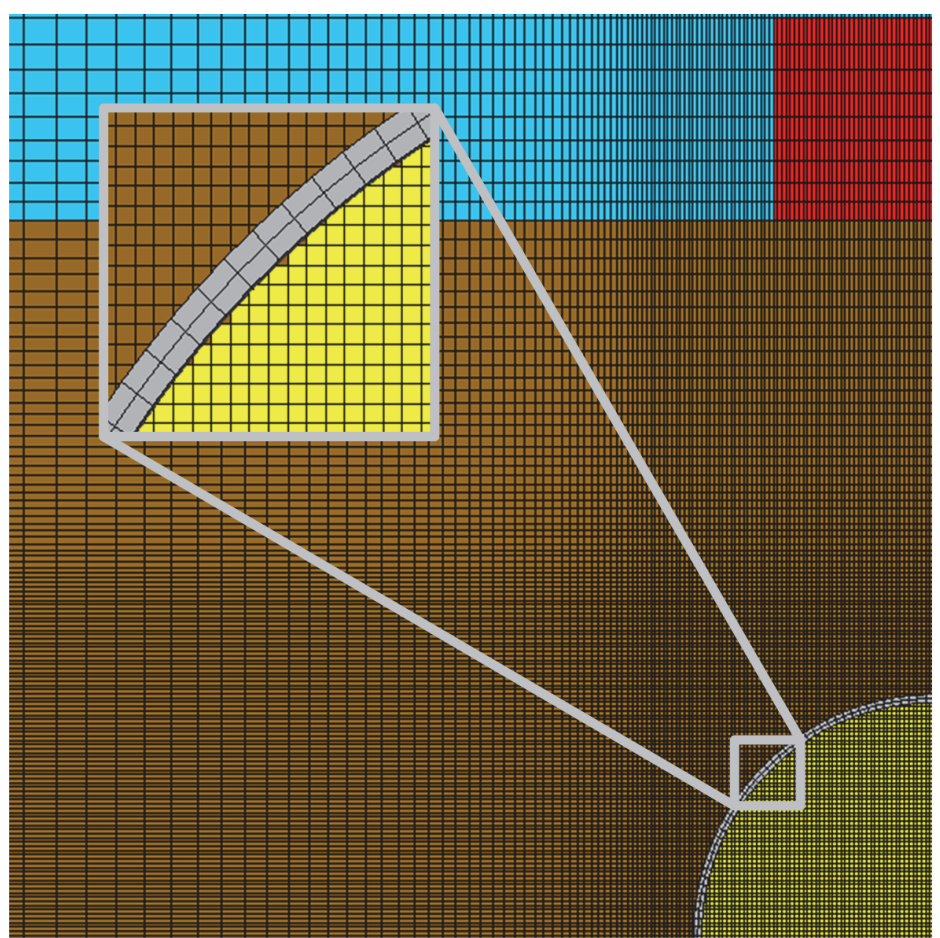

Fig. 2. Generated grids for 3-D model transversal section view and magnified view of pipeline elements

\section{Boundary and initial conditions}

Because of the symmetry in geometry and conditions, only a quarter of the domain was modeled, in which $x=0$ and $z=0$ are the symmetry planes. In order to prevent reflection of pressure waves from boundaries, the transmit boundary condition was considered in all boundaries. This boundary condition enables the material pressure flowing out without being reflected back into the domain and is described according to the Eq. (1) (Ambrosini \& Luccioni, 2006):

$$
P= \begin{cases}P_{r e f}+\left(U_{n}-U_{r e f}\right) I & \text { for } U_{n}>0 \\ P_{r e f} & \text { for } U_{n} \leq 0\end{cases}
$$

in which $U_{n}$ and $P$ are the normal velocity and pressure at boundary and $U_{\text {ref }}$ and $P_{\text {ref }}$ are the reference velocity and pressure, respectively. Moreover, $I$ is the material impedance, which is defined as $I=\rho \times$ soundspeed . Details of other boundary conditions and implemented areas are described in Table 1. Also, initial conditions of the simulations were imposed according to the real case accidents. In Table 2, details of the initial conditions are provided.

Table 1. Detailed descriptions of used boundary conditions (dimensions are in $\mathrm{m}$ )

\begin{tabular}{llll}
\hline BC Types & Imposed Environments & Implemented Areas & Description \\
\hline Symmetry & $\begin{array}{l}\text { Eulerian elements } \\
\text { Lagrangian elements }\end{array}$ & $x=0, z=0$ & $\begin{array}{l}\text { Variables gradients in direction normal to } \\
\text { the planes are zero. }\end{array}$ \\
Outflow & Eulerian elements & $x=7, z=10, y=16$ & $\begin{array}{l}\text { Entry and exit of Eulerian materials are } \\
\text { allowed. }\end{array}$ \\
Clamp & Lagrangian elements & $z=10$ & $\begin{array}{l}\text { All elements of the velocity vector at the } \\
\text { boundary are zero. }\end{array}$ \\
Infinite & Eulerian elements & $y=-16$ & $\begin{array}{l}\text { It is assumed that there are elements } \\
\text { outside the boundary which their values } \\
\text { are equal with values of inside elements. }\end{array}$ \\
\hline
\end{tabular}


Table 2. Detailed description of used initial conditions

\begin{tabular}{llll}
\hline IC Types & Imposed Environments & Implemented Materials & Description \\
\hline $\begin{array}{l}\text { Pressure } \\
\text { Temperature }\end{array}$ & Eulerian elements & Air and natural gas & $\begin{array}{l}\text { The pressure of air is equal to ambient and } \\
\text { the pressure of natural gas is equal to the } \\
\text { working pressure of the pipeline }(7 \mathrm{MPa}) .\end{array}$ \\
$\begin{array}{lll}\text { Velocity } \\
\text { Velocity }\end{array}$ & Eulerian elements & Air and natural gas & $\begin{array}{l}\text { Initial temperatures of Eulerian elements } \\
\text { are equal to ambient }(305 \mathrm{~K}) .\end{array}$ \\
\hline
\end{tabular}

\subsection{Fluid-structure interaction}

In problems that are engaged with the response of structures to explosions, fluid-structure interactions (FSIs) play a major role in the accuracy of the results. In these problems, separate solutions for the different physical fields (fluid and solid parts) are performed. At the boundary between fluids and solids, information for the solution is shared between the two domains. This information can be exchanged in one-way and two-way coupling methods. In the one-way-coupling method, the results of fluid domain are used as external forces in solid parts, and displacement and deformation are computed. This method needs low computational costs, but the accuracy of results can become enriched. In the two-way coupling method that is further divided into weakly and strongly coupling methods, the displacement and deformation of the structure are also applied to the fluid solver. In contrast, the twoway coupling method is more accurate in obtaining results, but has high computational costs. In this problem, to improve solution accuracy, fluid-structure interactions were applied according to conditions of Table 3.

Table 3. Applied FSI conditions in the simulations

\begin{tabular}{lll}
\hline Interaction Boundaries & Interaction Domains & Coupling Method \\
\hline Soil/pipeline & Eulerian/Lagrangian & Two-way/strongly-coupled \\
Air/pipeline & Eulerian/Lagrangian & Two-way/strongly-coupled \\
Natural gas/pipeline & Eulerian/Lagrangian & Two-way/strongly-coupled \\
Pipeline/pipeline & Lagrangian/Lagrangian & Self-interaction/strongly-coupled \\
\hline
\end{tabular}

\subsection{Materials properties}

In blast simulations, using appropriate numerical models for prediction of material properties is one of the most important tips in achieving acceptable results. Material models should predict relationship between pressure, stress, strain, specific volume (density), internal energy (temperature), resistance and failure of material in different conditions. Materials used in this paper include air, natural gas, explosive charge, steel, concrete and soil. Descriptions of numerical models for each material are expressed separately in the following paragraphs.

Numerical model for air and natural gas

One of the simplest and most practical equations of state (EOS) is ideal gas relation that is used to predict gases behaviors. This EOS is based on Boil and Gay-Lusaka laws and is shown in the Eq. (2) (Cengel \& Boles, 2015):

$$
P V=n R T
$$

where $P, V, n, R$ and $T$ are the pressure, volume, number of moles, ideal gas constant and temperature, respectively. In ideal gases, specific heat capacity only depends on temperature whereas in polytrophic ideal gases, heat capacity is directly proportional with temperature. For this type of gases, pressure relation with energy and therefore, temperature is according to the Eq. (3) (Cengel \& Boles, 2015):

$$
P=(\gamma-1) \rho \mathrm{e}
$$


in this equation, $\gamma, \rho$, and $\mathrm{e}$ are the heat capacity ratio, density and internal energy, respectively. Details of ideal gas properties for air and natural gas that were used in the simulations are presented in Table 4.

Table 4. Constants of ideal gas EOS for air and natural gas (Ambrosini \& Luccioni, 2006; Cengel \& Boles, 2015)

\begin{tabular}{lll}
\hline Material properties & Air & Natural Gas \\
\hline Base density $\left(\mathrm{kg} / \mathrm{m}^{3}\right)$ & 1.200 & 0.668 \\
Base temperature $(\mathrm{K})$ & 288.2 & 288.2 \\
Heat transfer coefficient at constant volume $(\mathrm{J} / \mathrm{kgK})$ & 717.3 & 1700.0 \\
Specific heat ratio & 1.406 & 1.300 \\
\hline
\end{tabular}

\section{Numerical model for explosive charge}

Among the equations of state describing behavior of explosion products, JWL, JWLB and BKW can be noted. Among these equations, because of the simplicity and ability to predict proper relationship between pressure, specific volume and internal energy, JWL EOS is the most widely used in numerical simulations. Jones-Wilkins-Lee (JWL) EOS shows thermodynamic properties of reacted and unreacted products of explosion and is described as (Baudin \& Serradeill, 2010):

$$
P=C_{1}\left(1-\frac{\omega}{\mathrm{R}_{1} v}\right) \exp \left(-\mathrm{R}_{1} v\right)+\mathrm{C}_{2}\left(1-\frac{\omega}{\mathrm{R}_{2} v}\right) \exp \left(-\mathrm{R}_{2} v\right)+\frac{\omega}{v} \mathrm{e}
$$

where $C_{1}, C_{2}, \mathrm{R}_{1}, \mathrm{R}_{2}$ and $\omega$ are the constants determined for each explosive by dynamic tests. These coefficients for TNT explosive are shown in Table 5.

Table 5. Parameters of JWL EOS for TNT (Baker et al., 2012)

\begin{tabular}{lllllll}
\hline Material Properties & $\mathrm{e}\left(\mathrm{J} / \mathrm{m}^{3}\right)$ & $\omega$ & $\mathrm{R}_{1}$ & $\mathrm{R}_{2}$ & $\mathrm{C}_{1}(\mathrm{MPa})$ & $\mathrm{C}_{2}(\mathrm{MPa})$ \\
\hline Magnitude & $6.0 \mathrm{e} 9$ & 0.35 & 4.15 & 0.90 & 373.77 & 3.74 \\
\hline
\end{tabular}

\section{Numerical model for steel}

In materials such as steel, volume changes caused by pressure are very low and thus, relation between them can be considered linear (Steinberg et al. 1980). Properties of this EOS for steel are shown in Table 6. In materials such as steel that has the ability to withstand shear stress, in addition to a relationship between pressure, energy and specific volume that is expressed by EOS, equations for resistance and failure of materials should also be mentioned. In these materials, yield stress is known as a criterion for determining the elastic or plastic behavior of materials. Johnson-Cook resistance equation is one of the most complete equations, which states yield stress changes in terms of strain, strain rate and temperature and is described as (Johnson et al., 1983; Seidt et al. 2007; Steinberg et al., 1980):

$$
Y=\left[A+B \varepsilon_{p}^{n}\right]\left[1+C \ln \varepsilon_{p}^{*}\right]\left[1-T_{H}^{m}\right]
$$

where $\varepsilon_{p}, \varepsilon_{p}^{*}$ and $T_{H}$ are the equivalent plastic strain in the material, normalized strain rate of the material and the homologous temperature, respectively. In this equation, constant factors are determined according to the experiments. These factors for steel are presented in Table 6. 
Table 6. Properties of Linear EOS and Johnson-Cook resistance equation for steel (Seidt et al., 2007)

\begin{tabular}{llll}
\hline Linear Equation of State & & Johnson-Cook Resistance Equation \\
\hline Material Properties & Magnitude & Material Properties & Magnitude \\
\hline Bulk modulus $(\mathrm{MPa})$ & $1.4 \mathrm{e} 5$ & Base yield stress $(\mathrm{MPa})$ & $4.48 \mathrm{e} 2$ \\
Base temperature $(\mathrm{K})$ & 300 & Strain linear coefficient $(\mathrm{MPa})$ & $2.43 \mathrm{e} 2$ \\
Specific heat capacity $(\mathrm{J} / \mathrm{kgK})$ & 486 & Strain power coefficient & $8.7 \mathrm{e}-2$ \\
Thermal conductivity $(\mathrm{J} / \mathrm{mKs})$ & 38 & Strain rate linear coefficient & $2.1 \mathrm{e}-2$ \\
& & Temperature power coefficient & $8.7 \mathrm{e}-2$ \\
\hline
\end{tabular}

There are various theories for determining the material failure criterion. In their simplest one, material failure depends only on stress or strain rate. However in reality, material failure depends on stress, strain and temperature. In new models for predicting material properties, all these parameters are considered. In this paper, Johnson-Cook failure model was used to calculate the degraded levels. This model uses a failure parameter D; accordingly, when the parameter value is equal to 1 , the final failure is to be expected. This parameter is defined as (Björklund, 2008):

$$
D=\int \frac{1}{\varepsilon_{f}} d \varepsilon_{e q}^{p},
$$

where $d \varepsilon_{e q}^{p}$ is the equivalent plastic strain increment and $\varepsilon_{f}$ is the failure equivalent strain that is defined as (Björklund, 2008; Johnson \& Cook, 1983, 1985):

$$
\varepsilon_{f}=\left(d_{1}+d_{2} e^{-d_{3} \frac{\sigma_{m}}{\sigma_{v M}}}\right)\left[1+d_{4} \ln \left(\frac{\dot{\varepsilon}_{e q}^{P}}{\dot{\varepsilon}_{0}}\right)\right]\left(1+d_{5} T\right)
$$

where $\mathrm{d}_{1}$ to $\mathrm{d}_{5}$ are the constants obtained from experiments. Also $\sigma_{\mathrm{m}}$ is the average of the Von-Mises stress, $\sigma_{\mathrm{vM}}$, the Von-Mises equivalent strain rate, $\dot{\varepsilon}_{e q}^{P}$, and the base strain rate, $\dot{\varepsilon}_{0}$. As shown in the Eq. (6) and Eq. (7), Johnson-Cook failure model is a function of strain, strain rate, temperature and threeway stress. In Table 7, properties of Johnson-Cook failure equation for steel are presented.

Table 7. Properties of Johnson-Cook failure equation for steel (Seidt et al., 2007)

\begin{tabular}{llllll}
\hline Coefficients & $d_{1}$ & $d_{2}$ & $d_{3}$ & $d_{4}$ & $d_{5}$ \\
\hline Magnitude & 0.243 & 1.240 & -2.525 & 0.004 & 0.250 \\
\hline
\end{tabular}

\section{Numerical model for soil}

Compaction EOS is one of the common equations of state in numerical modeling of soil properties, which gives a relationship between pressure and density according to the Eq. (8) (Grujicic et al., 2008; Grujicic \& Bell, 2011):

$$
P=C_{s}^{2}\left(\rho-\rho_{s}\right),
$$

where $C_{s}$ and $\rho_{s}$ are the sound speed and density of compact soil at zero pressure, respectively. Generally, loading and unloading of a porous material such as soil at every level of compaction are shown by a differential equation as the Eq. (9) (Grujicic et al., 2008; Grujicic \& Bell, 2011):

$$
\frac{\partial P}{\partial \rho}=C^{2}(\rho)
$$

where $C$ is the sound speed in soil with density of $\rho$. In the compaction equation, the initial density of soil can be obtained by using solid material density in the soil $\rho_{s}$, the water density $\rho_{w}$ and the porosity $\alpha=1-\rho_{l} / \rho_{s}$. This relation is shown by the Eq. (10) (Grujicic et al., 2008; Grujicic \& Bell, 2011). Properties of compaction EOS for soil are presented in Table 8. 


$$
\rho_{1, \text { sat }}=\rho_{s}(1-\alpha)+\rho_{\omega} \alpha .
$$

Table 8. Properties of compaction EOS for soil (Laine \& Sandvik, 2001)

\begin{tabular}{llll}
\hline Material properties & Magnitude & Material properties & Magnitude \\
\hline Density 1 $\left(\mathrm{kg} / \mathrm{m}^{3}\right)$ & 1,674 & Pressure 6 $(\mathrm{MPa})$ & 98.09 \\
Density 2 $\left(\mathrm{kg} / \mathrm{m}^{3}\right)$ & 1,740 & Pressure 7 $(\mathrm{MPa})$ & 179.44 \\
Density 3 $\left(\mathrm{kg} / \mathrm{m}^{3}\right)$ & 1,874 & Pressure 8 $(\mathrm{MPa})$ & 289.44 \\
Density 4 $\left(\mathrm{kg} / \mathrm{m}^{3}\right)$ & 1,997 & Pressure 9 $(\mathrm{MPa})$ & 450.19 \\
Density 5 $\left(\mathrm{kg} / \mathrm{m}^{3}\right)$ & 2,144 & Pressure 10 $(\mathrm{MPa})$ & 650.00 \\
Density 6 $\left(\mathrm{kg} / \mathrm{m}^{3}\right)$ & 2,250 & Sound speed 1 $(\mathrm{m} / \mathrm{s})$ & 265 \\
Density 7 $\left(\mathrm{kg} / \mathrm{m}^{3}\right)$ & 2,380 & Sound speed 2 $(\mathrm{m} / \mathrm{s})$ & 852 \\
Density $8\left(\mathrm{~kg} / \mathrm{m}^{3}\right)$ & 2,485 & Sound speed 3 $(\mathrm{m} / \mathrm{s})$ & 1,720 \\
Density 9 $\left(\mathrm{kg} / \mathrm{m}^{3}\right)$ & 2,585 & Sound speed 4 $(\mathrm{m} / \mathrm{s})$ & 1,875 \\
Density $10\left(\mathrm{~kg} / \mathrm{m}^{3}\right)$ & 2,671 & Sound speed 5 $(\mathrm{m} / \mathrm{s})$ & 2,265 \\
Pressure 1 $(\mathrm{MPa})$ & 0.00 & Sound speed 6 $(\mathrm{m} / \mathrm{s})$ & 2,956 \\
Pressure 2 $(\mathrm{MPa})$ & 4.58 & Sound speed 7 $(\mathrm{m} / \mathrm{s})$ & 3,112 \\
Pressure 3 $(\mathrm{MPa})$ & 14.98 & Sound speed 8 $(\mathrm{m} / \mathrm{s})$ & 4,600 \\
Pressure 4 $(\mathrm{MPa})$ & 29.15 & Sound speed 9 $(\mathrm{m} / \mathrm{s})$ & 4,634 \\
Pressure 5 $(\mathrm{MPa})$ & 59.17 & Sound speed 10 $(\mathrm{m} / \mathrm{s})$ & 4,634 \\
\hline
\end{tabular}

For numerical modeling of soil properties, in addition to EOS, resistance and failure equations are also needed. Drucker-Prager resistance model is a practical model, which is used to express the behavior of dry soil, rocks, cement and ceramic. In other words, this equation is appropriate for materials that their shear resistance has direct relation with applied loads (Chen \& Mizuno, 1990).

Mo-Granular is a development of the Drucker-Prager model, which measures effects related to granular materials such as powder, soil and sand. In this model, in addition to pressure hardening, density hardening and change of shear modulus with density are also included and yield stress is assumed to be a composition of two components: one related to density and other related to pressure (Grujicic et al., 2008; Grujicic \& Bell, 2011).

$$
\sigma_{y}=\sigma_{p}+\sigma_{\rho} .
$$

Here, $\sigma_{y}, \sigma_{p}$ and $\sigma_{\rho}$ point to the total yield stress, yield stress associated with pressure and yield stress associated with density, respectively. In this model, same as Drucker-Prager, the relationship between yield stress and pressure is calculated by experiments and expressed as a polynomial. In addition to the relationship between pressure and yield stress, a relationship based on density and yield stress should be also expressed. In Table 9, coefficients of Drucker-Prager resistance equation for soil are provided.

Table 9. Properties of Drucker-Prager resistance equation for soil (Laine \& Sandvik, 2001)

\begin{tabular}{llll}
\hline Material Properties & Magnitude & Material Properties & Magnitude \\
\hline Pressure 1 $(\mathrm{MPa})$ & 0.00 & Density $5\left(\mathrm{~kg} / \mathrm{m}^{3}\right)$ & 2,300 \\
Pressure 2 $(\mathrm{MPa})$ & 3.40 & Density 6 $\left(\mathrm{kg} / \mathrm{m}^{3}\right)$ & 2,572 \\
Pressure 3 $(\mathrm{MPa})$ & 34.90 & Density $7\left(\mathrm{~kg} / \mathrm{m}^{3}\right)$ & 2,598 \\
Pressure 4 $(\mathrm{MPa})$ & 101.34 & Density $8\left(\mathrm{~kg} / \mathrm{m}^{3}\right)$ & 2,635 \\
Pressure 5 $(\mathrm{MPa})$ & 184.65 & Density $9\left(\mathrm{~kg} / \mathrm{m}^{3}\right)$ & 2,641 \\
Pressure 6 $(\mathrm{MPa})$ & 500.00 & Density 10 $\left(\mathrm{kg} / \mathrm{m}^{3}\right)$ & 2,800 \\
Yield stress 1 $(\mathrm{MPa})$ & 0.00 & Shear modulus 1 $(\mathrm{MPa})$ & 77 \\
Yield stress 2 $(\mathrm{MPa})$ & 4.24 & Shear modulus 2 $(\mathrm{MPa})$ & 869 \\
Yield stress 3 $(\mathrm{MPa})$ & 44.70 & Shear modulus 3 $(\mathrm{MPa})$ & 4,032 \\
Yield stress 4 $(\mathrm{MPa})$ & 124.04 & Shear modulus 4 $(\mathrm{MPa})$ & 4,907 \\
Yield stress 5 $(\mathrm{MPa})$ & 226.00 & Shear modulus 5 $(\mathrm{MPa})$ & 7,769 \\
Yield stress 6 $(\mathrm{MPa})$ & 226.00 & Shear modulus 6 $(\mathrm{MPa})$ & 14,800 \\
Density 1 $\left(\mathrm{kg} / \mathrm{m}^{3}\right)$ & 1,674 & Shear modulus 7 $(\mathrm{MPa})$ & 16,570 \\
Density 2 $\left(\mathrm{kg} / \mathrm{m}^{3}\right)$ & 1,746 & Shear modulus 8 $(\mathrm{MPa})$ & 36,710 \\
Density 3 $\left(\mathrm{kg} / \mathrm{m}^{3}\right)$ & 2,086 & Shear modulus 9 $(\mathrm{MPa})$ & 37,347 \\
Density 4 $\left(\mathrm{kg} / \mathrm{m}^{3}\right)$ & 2,147 & Shear modulus 10 $(\mathrm{MPa})$ & 37,347 \\
\hline
\end{tabular}


Failure criterion used for soil is minimum hydrostatic stress. This criterion states that for stresses lesser than minimum hydrostatic stress, the material fails and does not have the ability to withstand shear or tensile stresses. In fact, this criterion is based on soil particle separation in tension (Chen \& Mizuno, 1990).

\section{Numerical model for concrete}

For numerical modeling of concrete properties, P alpha EOS, RHT concrete resistance and RHT concrete failure equations are used. The accuracy of these models in prediction of concrete response to blast loads is confirmed in $\mathrm{Hu}$ et al.'s study (Hu et al. 2014). The related coefficients for these models are presented in Tables 10 to 12 .

Table 10. Parameters of $\mathrm{P}$ alpha EOS (Hu et al., 2014)

\begin{tabular}{llll}
\hline Parameters & Magnitude & Parameters & Magnitude \\
\hline Reference density $\left(\mathrm{kg} / \mathrm{m}^{3}\right)$ & $2.75 \mathrm{e} 3$ & Initial compaction pressure $(\mathrm{MPa})$ & 23.30 \\
Porous density $\left(\mathrm{kg} / \mathrm{m}^{3}\right)$ & $2.31 \mathrm{e} 3$ & Solid compaction pressure $(\mathrm{MPa})$ & $6.00 \mathrm{e} 3$ \\
Porous sound speed $(\mathrm{m} / \mathrm{s})$ & $2.90 \mathrm{e} 3$ & Specific heat $(\mathrm{J} / \mathrm{kgK})$ & $7.00 \mathrm{e} 2$ \\
Reference temperature $(\mathrm{K})$ & 293 & Compaction exponent & 3.00 \\
\hline
\end{tabular}

Table 11. Parameters of RHT concrete resistance equation (Hu et al., 2014)

\begin{tabular}{llll}
\hline Parameters & Magnitude & Parameters & Magnitude \\
\hline Shear modulus (MPa) & $1.6 \mathrm{e} 4$ & G: Elastic/(elastic-plastic) & 2.00 \\
Compressive strength (MPa) & 3.78 & Elastic/tensile ratio & 0.70 \\
Tensile strength ratio & 0.10 & Elastic/compressive ratio & 0.70 \\
Shear strength ratio & 0.18 & Fractured strength constant & 1.60 \\
Intact failure surface constant & 1.60 & Fractured strength exponent & 0.50 \\
Intact failure surface exponent & 0.61 & Compressive strain rate exponent & 0.05 \\
Tensile/Compressive ratio & 0.68 & Tensile strain rate exponent & 0.02 \\
Brittle to ductile transition & 0.01 & Maximum fracture strength ratio & $1.00 \mathrm{e} 18$ \\
\hline
\end{tabular}

Table 12. Parameters of RHT concrete failure equation (Hu et al., 2014)

\begin{tabular}{ll}
\hline Parameters & Magnitude \\
\hline D1 & $1.4 \mathrm{e} 8$ \\
D2 & $1.0 \mathrm{e} 0$ \\
Minimum strain to failure & $1.0 \mathrm{e}-3$ \\
Residual shear modulus fraction & $1.3 \mathrm{e}-1$ \\
\hline
\end{tabular}

\subsection{Validation of numerical method}

For validation of the numerical method, 3 benchmark experiments in the field of explosion were reproduced and results were compared. In the following paragraphs, details of these experiments and the results are discussed.

\section{Incipient and reflected pressure waves}

In 1990, US Army in cooperation with the Navy and Air Force (Castellano et al., 1990) investigated the incipient and reflected blast waves. The incipient wave is the initial pressure wave that is released from an explosion. When an incipient wave collides with a rigid body, pressure waves become reflected from the body, which is referred as the reflected pressure wave. Due to conversion of kinetic energy to potential energy, the magnitude of reflected waves is about 8-12 times more than that of the incipient pressure wave (Son \& Lee, 2011).

In Fig. 3, the incipient and reflected pressure waves are plotted versus time. The incipient and reflected pressure waves were created from explosion of $45.4 \mathrm{~kg}$ TNT in the distance of $3.81 \mathrm{~m}$ and $2.54 \mathrm{~m}$, respectively. In this figure, the data obtained from the experiment (Castellano et al., 1990), the numerical results of Son and Lee's study (Son \& Lee, 2011) and numerical results of the current study are shown with positive black signs, red dots and blue dash lines, respectively. Results showed that the experimental data and the results of the present study were in an acceptable consistency, and accuracy of the numerical method was confirmed. 

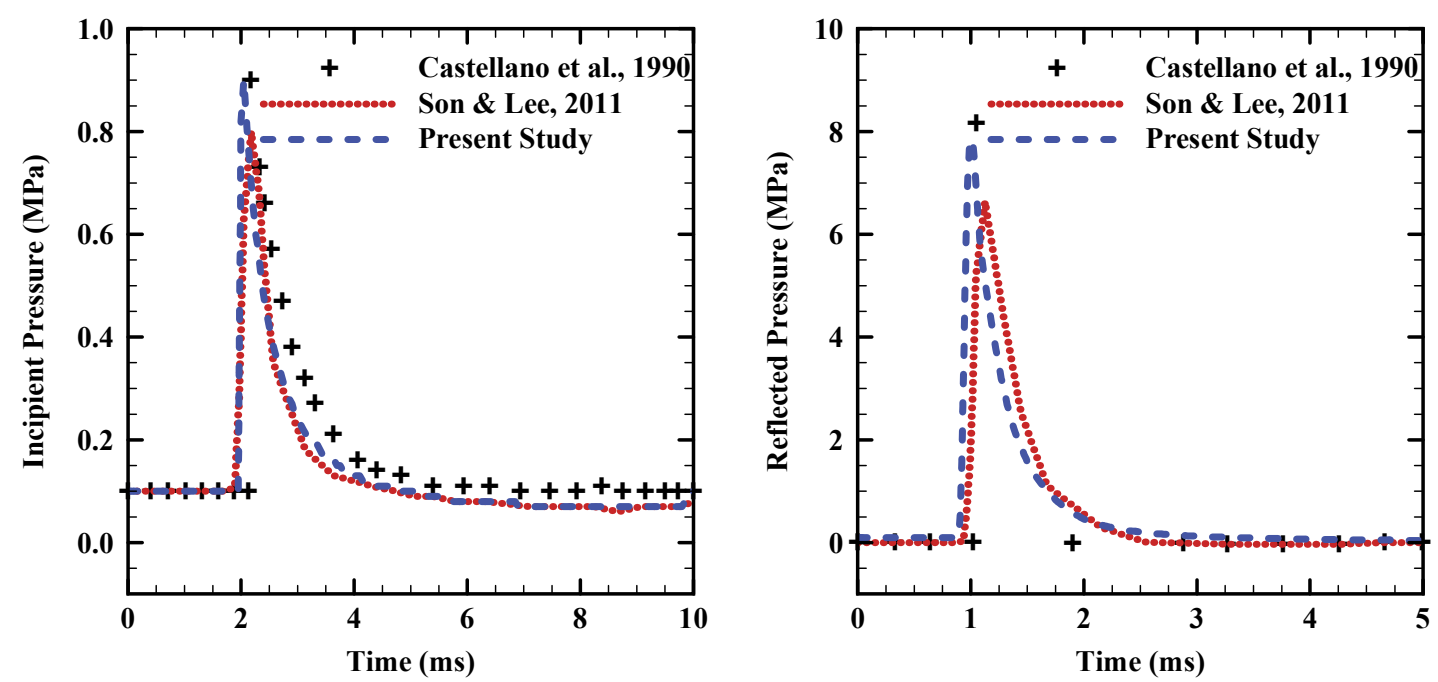

Fig. 3. Validation of the numerical method- diagram of incipient and reflected pressure waves versus time

\section{Crater creation in surface explosion}

In case of terrorist attacks or other intentional actions using explosives, very valuable information can be obtained from the created craters. For example, distance of explosive charge from ground level and quantity of explosive charges can be deduced from dimensions of the created craters. Ambrosini's research team (Ambrosini et al., 2004; Ambrosini \& Luccioni, 2012; Ambrosini et al., 2002; Ambrosini \& Luccioni, 2006; Luccioni et al., 2009) carried out noteworthy analytical, experimental and numerical studies in the field of crater creation from explosion charges. For validation of the numerical method, the results of the current study and Ambrosini and Luccioni's study (Ambrosini \& Luccioni, 2012) in estimating the diameter of the produced crater due to various TNT masses are compared in Table 13. This table shows that for TNT masses of 1,7 and $10 \mathrm{~kg}$, the crater with diameters of $0.54,1.32$ and $1.42 \mathrm{~m}$ is created. Maximum differences between the experimental data and numerical results are about $8 \%$. With respect to this article, this difference is insignificant and acceptable. Therefore, we can conclude that the numerical method has the ability to predict the appropriate blast wave-soil interaction.

Table 13. Validation of the numerical method-estimated diameters of craters versus different explosive mass charges

\begin{tabular}{|c|c|c|c|c|c|}
\hline \multirow[b]{2}{*}{$\begin{array}{l}\text { Explosive } \\
\text { Charges (kg) }\end{array}$} & \multirow[b]{2}{*}{ Mass } & \multicolumn{3}{|l|}{ Crater Diameter (m) } & \multirow[b]{2}{*}{$\begin{array}{l}\text { Difference of } \\
\text { Current Study and } \\
\text { Experimental Data } \\
(\%)\end{array}$} \\
\hline & & $\begin{array}{l}\text { Ambrosini } \\
\text { Experimental } \\
\text { Results ( Ambrosini } \\
\text { \& Luccioni, 2012) } \\
\end{array}$ & $\begin{array}{lr}\text { Ambrosini } & \\
\text { Numerical } & \text { Results } \\
\text { (Ambrosini } & \& \\
\text { Luccioni, 2012) } & \\
\end{array}$ & $\begin{array}{l}\text { Results of Current } \\
\text { Study }\end{array}$ & \\
\hline 1 & & 0.58 & 0.60 & 0.54 & 6.90 \\
\hline 7 & & 1.48 & 1.12 & 1.32 & 10.81 \\
\hline 10 & & 1.56 & 1.54 & 1.42 & 8.97 \\
\hline
\end{tabular}

\section{Results and discussions}

Responses of a buried 56-inch diameter high pressure gas pipeline to surface explosions were numerically simulated and the results are presented and discussed in this section. Besides the main aim, to improve safety of these lines, some parametric studies on the effects of explosive mass, pipeline thickness, burial depth and concrete protective layer on pipeline deformation were also performed and results are discussed in next paragraphs. 


\subsection{Effects of mass charges on pipeline deformation}

In surface explosions, due to the energy absorbing property of soil, large masses of explosive charge are needed to make damages in buried equipment. Therefore, to study the effects of explosive masses on pipeline deformation, 150, 350, 650 and $900 \mathrm{~kg}$ TNT are simulated. For determination of pipeline deformation, $f=d D / D$ and $\dot{f}=\frac{d D / D}{d t}$ factors are defined, which specify the pipeline strain and strain rate, respectively.

In Fig. 4, changes of the deformation $(f)$ and deformation rate $(\dot{f})$ are plotted versus time for the abovementioned explosive masses. Results show that pipeline deformation increases to a maximum value and then, because of the elasticity of steel and working pressure of the pipeline (pressure of natural gas), it gradually decreases and tends toward a constant value. For smaller mass values, this trend can be clearly seen from Fig. 4. For example, for $150 \mathrm{~kg}$ TNT, the maximum strain value is reached in about $10 \mathrm{~ms}$ and in about $20 \mathrm{~ms}$, the pipeline deformation rate factor is zero and pipeline deformation reaches its constant value of 0.01 .

Results also show that there is a delay time between the explosion time and the time that the blast affects the pipeline. This delay time depends on sound speed in soil, burial depth and detonation point. According to the results, it is clear that delay time is reduced by increasing explosive masses. For explosive masses of 900 and $150 \mathrm{~kg}$, the delay time increases from 1.4 to $2.2 \mathrm{~ms}$.

As expected, results of Fig. 4 illustrate that pipeline deformation grows by increasing explosive masses. The deformation growths are due to the larger amount of stored energy in larger values of explosive charge, which could create blast waves with larger amplitudes. For $900 \mathrm{~kg}$ TNT, the deformation factor of the pipeline reaches 0.65 at time $=20 \mathrm{~ms}$, which makes the pipeline unusable.
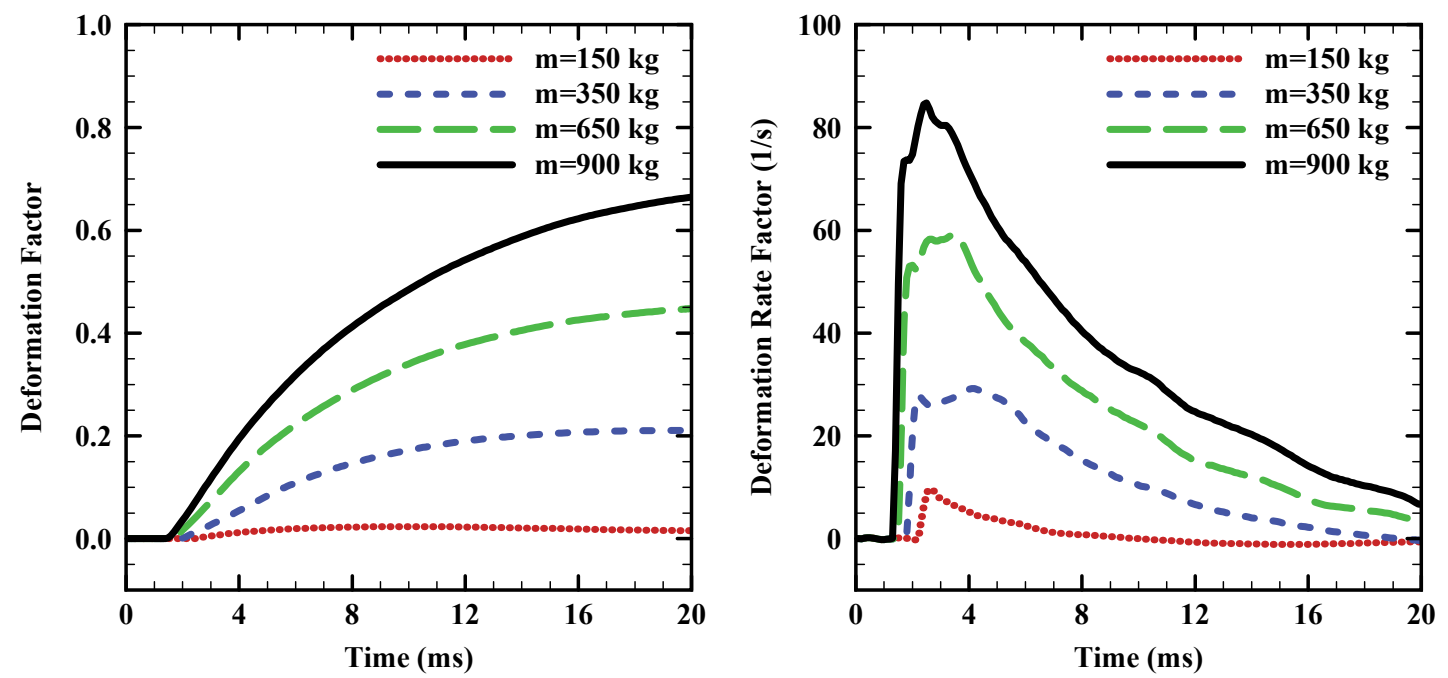

Fig. 4. Pipeline deformation and deformation rate factors versus time for different masses of explosive charges

In Fig. 5, contours of Von-Mises stress for 150 and 900kg explosive charge are shown in different times after explosion. Results of this figure also confirm the delay time between the explosion and impact of the blast wave with the pipeline. In other words, due to the burial depth and existence of soil material between the pipeline and explosive charge, in earlier times, the pipeline did not feel any considerable stresses. In the case of $150 \mathrm{~kg}$ TNT mass, soil absorbed the generated blast waves and maximum Von-Mises stress of the pipeline was about 400MPa. This result indicates that buried pipelines have good protection layer (soil) and could withstand against medium masses of explosive charges. In the case of $900 \mathrm{~kg}$ TNT, after about $2 \mathrm{~ms}$, the blast wave reached the pipeline and Von-Mises stresses increased sharply. 


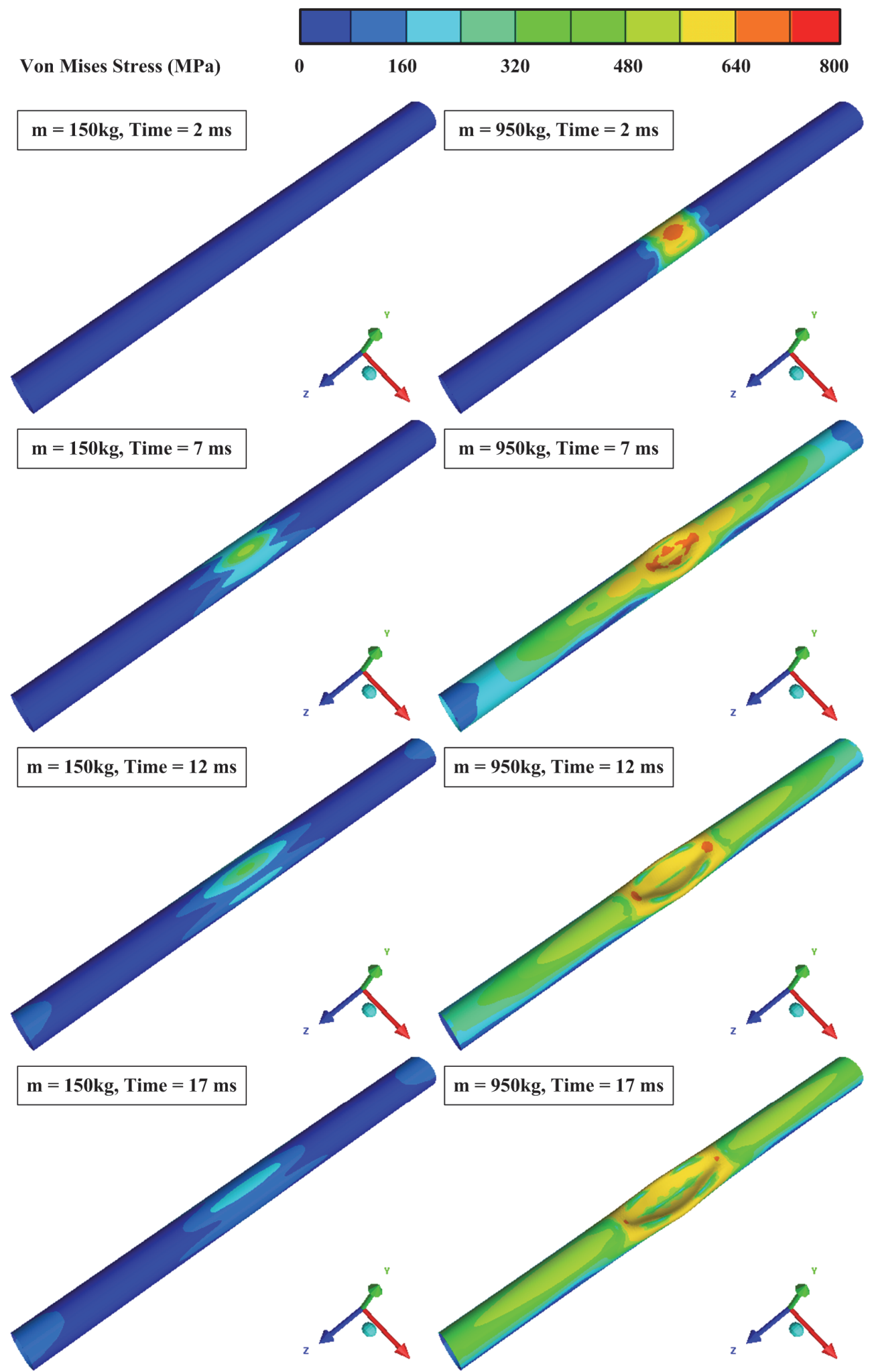

Fig. 5. Contours of Von Mises stress in pipeline in different times after explosion for $m=150 \mathrm{~kg}$ (left pictures) and $\mathrm{m}=900 \mathrm{~kg}$ (right pictures) explosive charges 
Maximum Von-Mises stresses in the pipeline were about $600 \mathrm{MPa}$, which were more than that of the base yield stress of steel (448MPa according to Table 6). This trend shows that in the numerical model of steel, effects of the strain and strain rate on final yield stresses are considered properly. Results of this figure show that the blast wave bent down the upper parts of the pipeline and at time $=20 \mathrm{~ms}$, about $6 \mathrm{~m}$ of the pipeline deformed permanently and became unusable. In the next parametric studies, mass of the TNT is considered equal to $900 \mathrm{~kg}$ (the biggest value of this part) and effects of other parameters are studied.

\subsection{Effects of pipeline thicknesses on pipeline deformation}

To investigate effects of the pipeline thicknesses on its deformations, 15, 25, 35 and $45 \mathrm{~mm}$ thicknesses are considered in numerical models. In Fig. 6, changes of the deformation $(f)$ and deformation rate $(\dot{f})$ factors are plotted versus time for the abovementioned thicknesses. As can be seen, increase in thicknesses reduces the pipeline strain as well as the pipeline strain rate except for the case where $t=15 \mathrm{~mm}$. In this case, the pipeline is crumpled like a shell (Fig. 7). For the $45 \mathrm{~mm}$ thickness, the pipe strain reached its maximum value of 0.30 and then, due to its elastic characteristic, decreased to its ultimate value. For lower thicknesses, this event is taken place in longer times and in larger strain values. It could be concluded that by increasing the pipe thickness from 25 to $45 \mathrm{~mm}$, its deformation decreases about $55 \%$.

For a closer look, material statuses for the thicknesses of 15, 25, 35 and $45 \mathrm{~mm}$ are compared in Fig. 7. In this figure, contours of the material status are presented in isometric and transversal section views at time $=20 \mathrm{~ms}$. It is clear that longitudinal and diagonal strain of the pipelines decreases by increasing the pipeline thickness. In the $25 \mathrm{~mm}$ thickness, large parts of the pipeline (about $30 \%$ ) changed to the plastic form. In the case of $45 \mathrm{~mm}$ thickness, the pipe strain is low and only little parts of the pipeline (about 5\%) changed from elastic to plastic status. However, due to stress concentration in the dented areas, gas leakage during the SCC (stress corrosion cracking) process is possible. Therefore, for safety issues in future functions, it is better to replace the plastic length of the pipeline with new elastic parts.
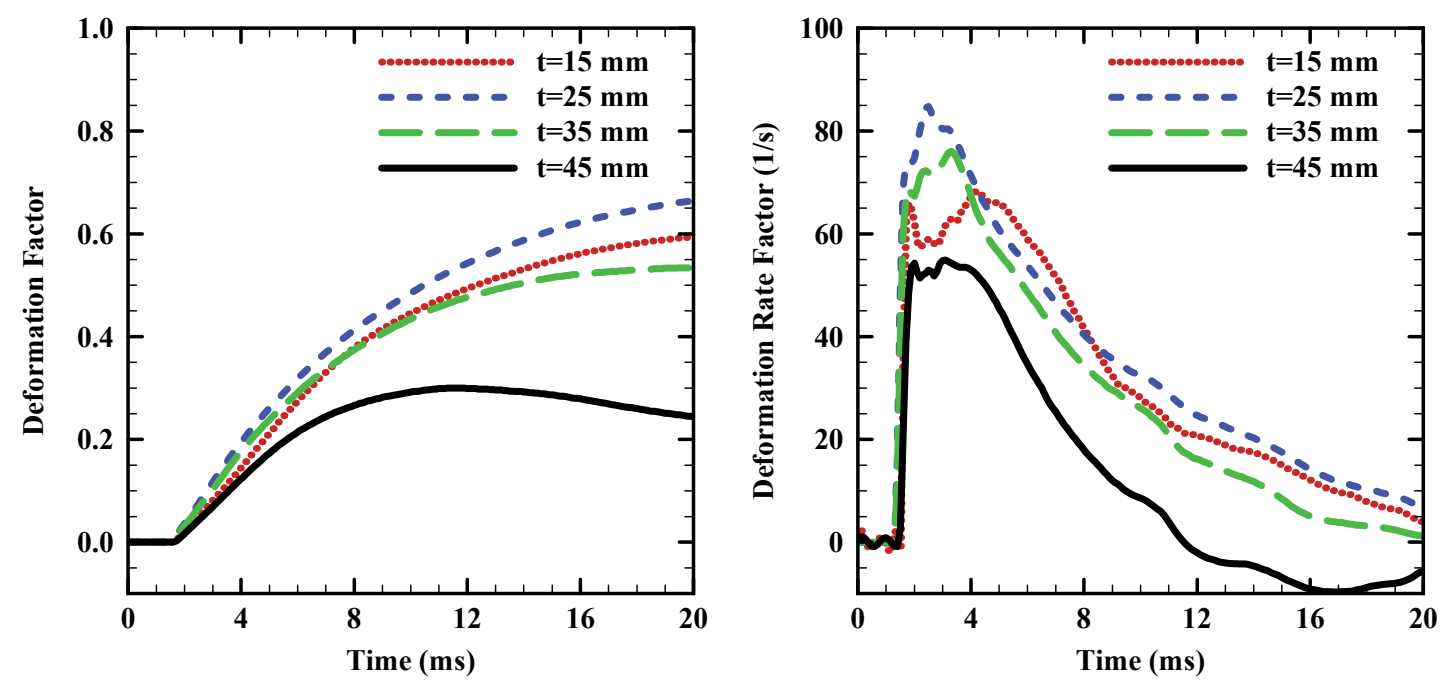

Fig. 6. Pipeline deformation and deformation rate factors versus time for different thicknesses of pipe 


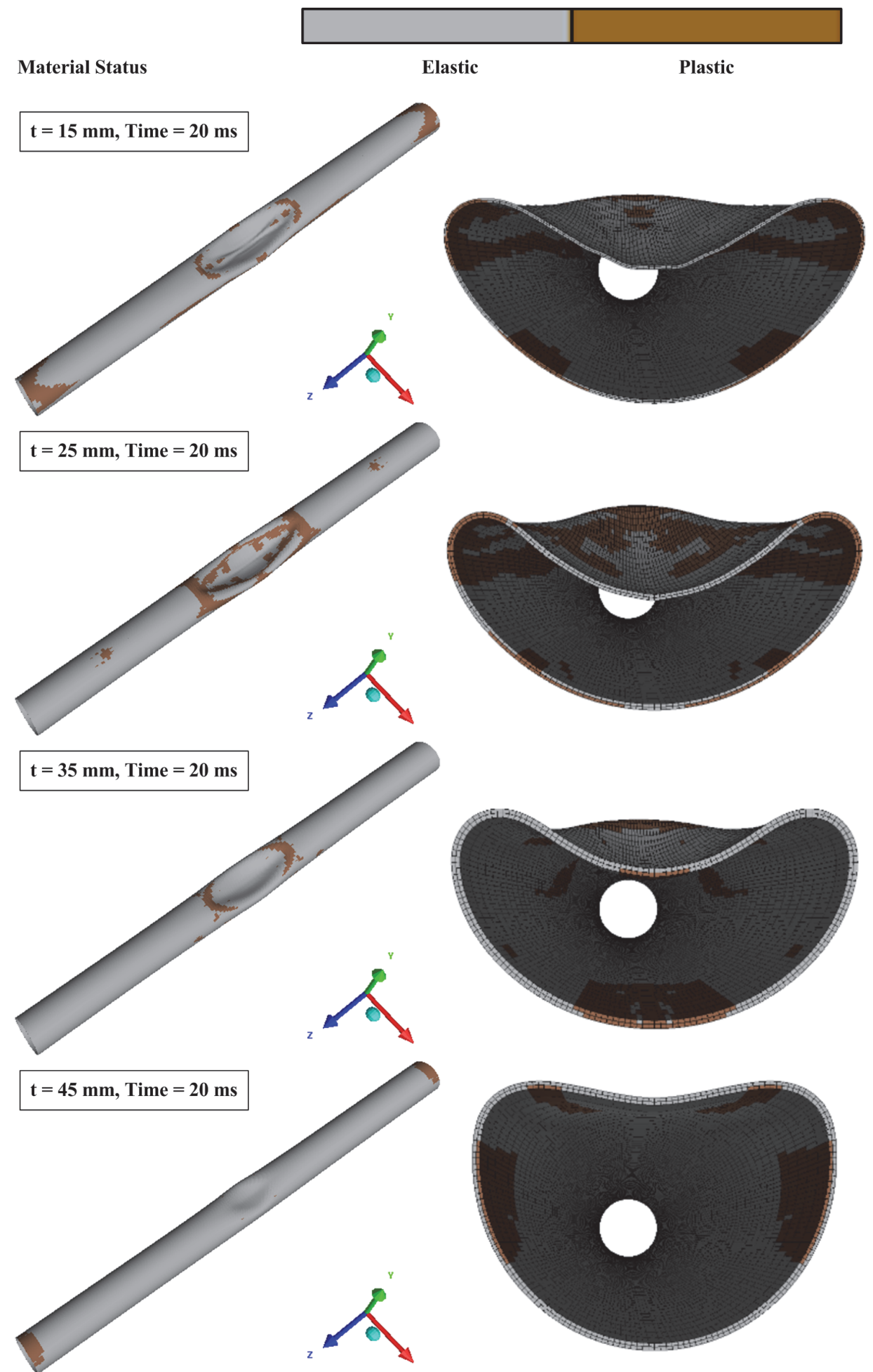

Fig. 7. Contours of material status at time $=20 \mathrm{~ms}$ for 4 different pipe thicknesses isometric and transversal section views

\subsection{Effects of burial depth on pipeline deformation}

Standard burial depth (distance from top of the pipeline to ground surface) for underground high pressure gas pipelines is about $1 \mathrm{D}$, where $\mathrm{D}$ is the internal diameter of the pipeline. Therefore, for 56inch diameter pipelines, burial depth is about $1.4 \mathrm{~m}$. In this study, to investigate the effects of burial depth, 1.0, 1.8 and 2.2m burial depths are considered. In Fig. 8, changes of the deformation and deformation rate factors are plotted versus time for the abovementioned conditions. It could be observed that by decreasing the burial depth, the pipeline deformation increases and pressure waves reach the 
pipeline in shorter times. It is observed that for $1.0,1.4,1.8$ and $2.2 \mathrm{~m}$ burial depths, the delay time is $0.8,1.4,2.3$ and $3.0 \mathrm{~ms}$, respectively. It could be concluded that by increasing the burial depth from 1.4 to $2.2 \mathrm{~m}$, the maximum strain of the pipeline is reduced about $70 \%$. Hence, to increase the safety of pipelines in strategic areas, operating pipelines in deeper depths could be a good idea.
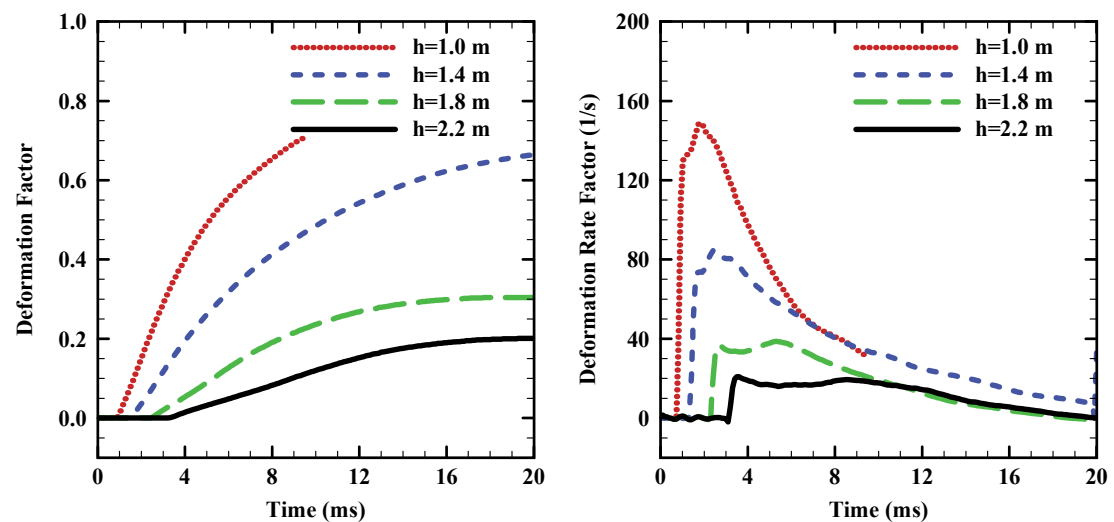

Fig. 8. Pipeline deformation and deformation rate factors versus time for different burial depths

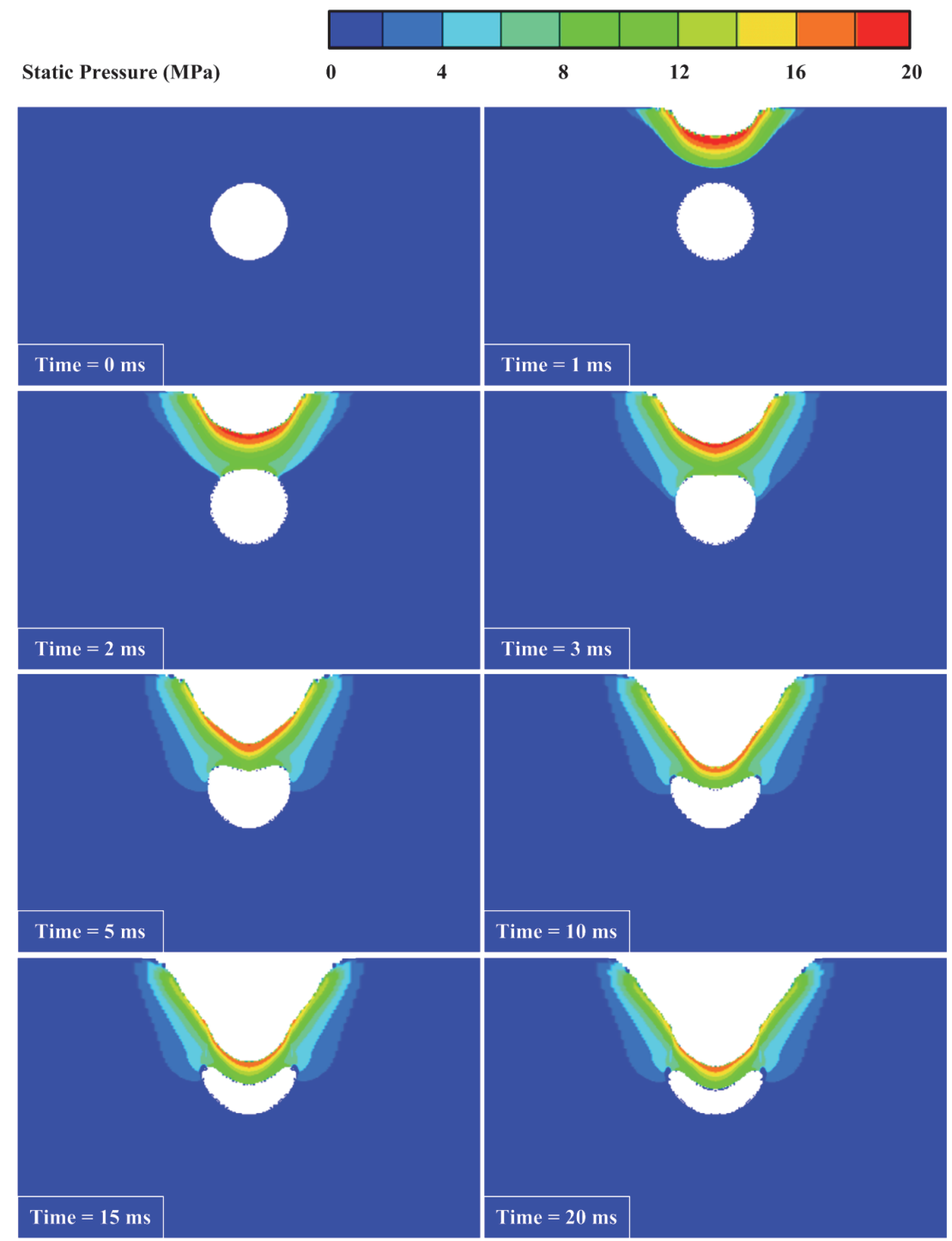

Fig. 9. Contours of static pressure at $\mathrm{z}=0$ plane in soil in different times after explosion 
Results show that energy absorbing property of soil reduces the amplitude of blast waves and shorter burial depths could be followed by excessive damages. In this case, the pipeline buried in depth of $1 \mathrm{~m}$ only tolerated the blast wave until $9.5 \mathrm{~ms}$ and then, due to large deformation of the pipeline, the simulation was ended.

For investigation on absorbing effects of soil in explosion events, contours of static pressure in soil in different times after explosion are presented in Fig. 9. For better comprehension, the results at the $\mathrm{z}=0$ plane are presented. Results indicate that the blast wave creates a crater below the detonation point, in which its diameter increases with time until the energy of explosive material diminishes. It could be concluded that the dimensions of the numerical model are large enough and the boundaries did not influence the results. Also, the transmit boundary condition was adjusted properly and the pressure waves did not reflect from the boundaries.

\subsection{Effects of concrete protective layer on pipeline deformation}

One of the suggested ways to reduce the effects of impact energy released from explosion is using absorbing protective layers. For this purpose, to examine the effects of a concrete protective layer on the safety of the buried pipelines, layers of concrete with thicknesses of 100, 200 and 300mm were considered on the soil surface.

In Fig. 10, changes of the deformation and deformation factors are plotted versus time for these conditions. Interesting behavior of the concrete protective layer on the reduction of the pipeline deformations is seen from this figure. For a thin layer of concrete, concrete acts reversely and increases the deformation of the pipeline. By increasing the thickness of the layer, it acts as an energy absorbing layer and reduces the amplitude of blast wave and as a result, the pipeline strain decreases. This trend is due to the compressibility, shear modulus and density of concrete particles. In other words, in thin layers of concrete, due to higher compressibility and density, blast waves pass stronger and faster in concrete domains than in soil domains. By increasing the concrete thickness, resistances of concrete particles absorb the penetrated energy and reduce the magnitude of blast waves. It could be concluded that to enhance the safety of underground pipelines, concrete layers with specific thicknesses should be used.
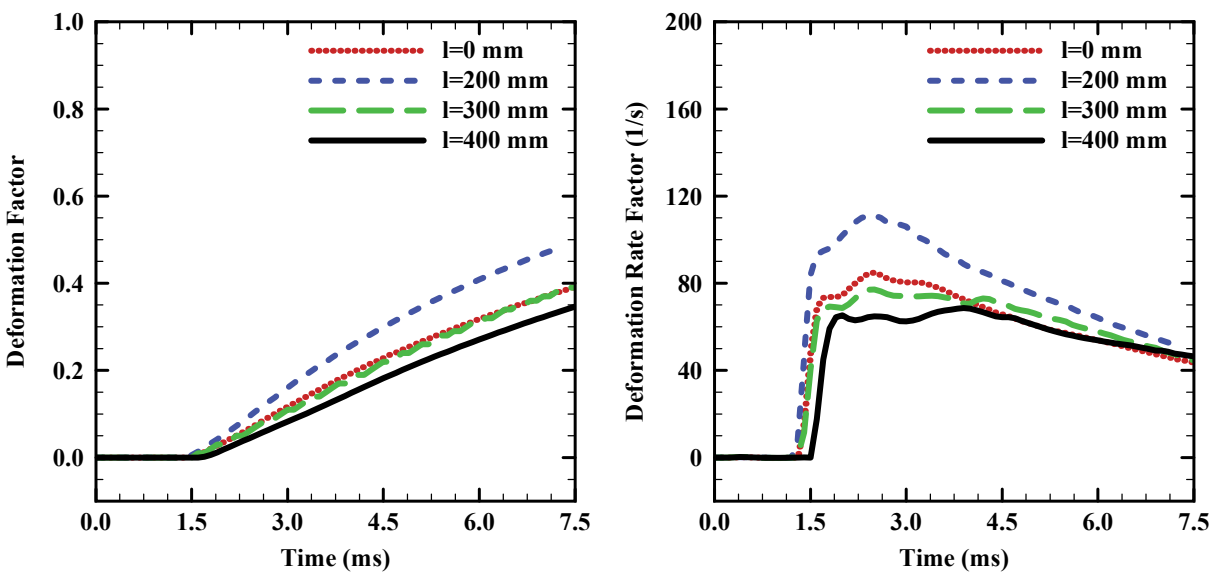

Fig. 10. Pipeline deformation and deformation rate factors versus time for different thicknesses of concrete protective layers

To investigate the movements of materials in explosion events, contours of materials location are presented in Fig. 11. Results show that explosive products expand rapidly and in few instants, the domain is influenced by them. Expansion of explosion products pushes out the surrounding air and makes a blast wind. Also, due to the released energy of the explosive charge, the soil and concrete particles are thrown out and a crater is created under the detonation point. In this case, due to large amount of the explosive charge, the concrete protective layer is broken down, soil is scattered away and the blast wave impacts the pipeline and as a result, upper parts of the pipeline become dented and deformed. 


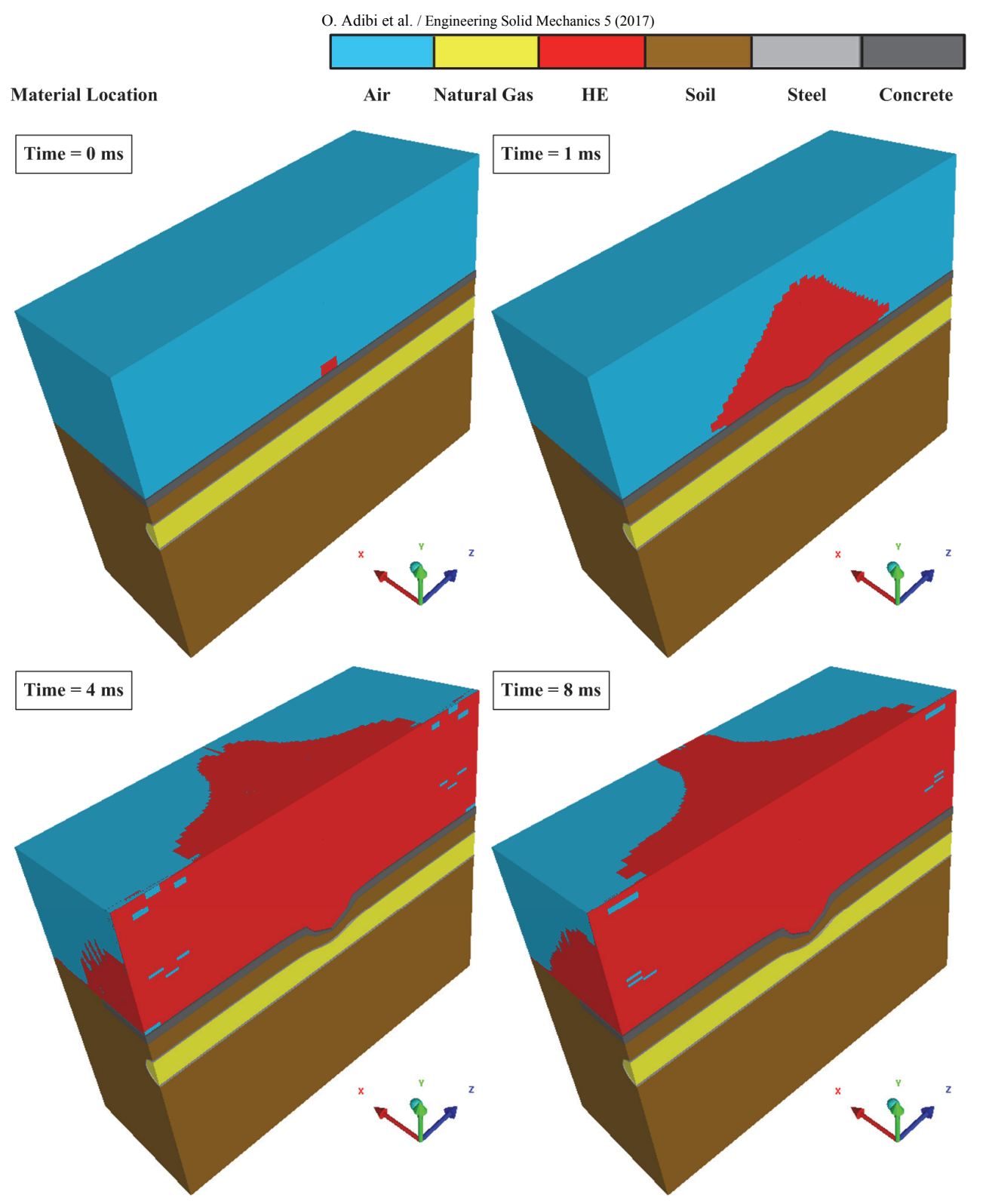

Fig. 11. Contours of material location in different times after explosion- Longitudinal section view.

\section{Conclusion}

In this study, to enhance the safety of buried lines, the responses of a buried 56-inch diameter high pressure gas pipeline to surface blasts were numerically investigated. In the simulations, to improve the accuracy of the results, dimensions were modeled in real scales, grids were generated by 8-node block Eulerian and Lagrangian elements, materials behavior was predicted by high accurate material property models and fluid-structure interaction was considered by two-way FSI methods. For validation of the numerical method, three benchmark experiments in the field of mass charge explosion were reproduced. Comparison of the results indicated that the numerical method could predict incipient and reflected pressure waves and crater creation in accordance with the experimental data.

Numerical results showed that explosion of $900 \mathrm{~kg}$ TNT deformed $6 \mathrm{~m}$ of the pipeline permanently and made them unusable. In this case, the maximum strain of the pipeline reached 0.65 . For smaller explosive charges, the length of the deformed parts and the strain factor of the pipeline were lower. The study of the effects of the pipeline thickness on its deformation showed that by increasing the pipe 
thickness from 25 to $45 \mathrm{~mm}$, its deformation decreased by about $66 \%$. For lower thicknesses $(15 \mathrm{~mm})$, surface blast squishes the pipeline like a shell and makes it useless.

Also, investigation of the effects of burial depth on the pipeline deformation showed that soil is a great energy absorbing domain and by increasing the burial depth from 1.4 to $2.2 \mathrm{~m}$, the strain of the pipeline was reduced by $71 \%$. The results also showed that using concrete protective layers could act reversely and increase the pipeline deformation. In other words, to enhance the safety of pipelines, a certain thickness of concrete layer is required.

\section{References}

Alonso, F. D., Ferradas, E. G., Minarro, M. D., Aznar, A. M., Gimeno, J. R., \& Perez, J. F. S. (2008). Consequence analysis by means of characteristic curves to determine the damage to buildings from the detonation of explosive substances as a function of TNT equivalence. Journal of Loss Prevention in the Process Industries, 21(1), 74-81.

Ambrosini, R. D., Luccioni, B. M., Danesi, R. F., Riera, J. D., \& Rocha, M. M. (2002). Size of craters produced by explosive charges on or above the ground surface. Shock Waves, 12(1), 69-78.

Ambrosini, R. D., Luccioni, B. M., \& Danesi, R. F. (2004). Influence of the soil properties on craters produced by explosions on the soil surface. Mec'anica Computacional, 23, 571-590.

Ambrosini, R. D., \& Luccioni, B. M. (2006). Craters produced by explosions on the soil surface. Journal of Applied Mechanics, 73(6), 890-900.

Ambrosini, R. D., \& Luccioni, B. M. (2012). Craters produced by explosions on, above and under the ground. In H. Hao \& Z. X. Li (Eds.), Advances in Protective Structures Research (pp. 365-396). London, UK: CRC Press.

Baker, E. L., Murphy, D., Stiel, L. I., \& Wrobel, E. (2012). Theory and calibration of JWL and JWLB thermodynamic equations of state. WIT Transactions on State of the Art in Science and Engineering, $60,41-52$.

Baudin, G., \& Serradeill, R. (2010). Review of Jones-Wilkins-Lee equation of state. EPJ Web of Conferences, 10(21), 1-4.

Baylot, J. T., Bullock, B., Slawson, T. R., \& Woodson, S. C. (2005). Blast response of lightly attached concrete masonry unit walls. Journal of Structural Engineering, 131(8), 1186-1193.

Bjorklund, O. (2008). Modelling of failure (Master's thesis). Retrived from http://www.divaportal.org/smash/get/diva2:17900/FULLTEXT01.pdf.

Castellano, A. J., Caltagirone, J., Sock, F. E., \& Dobbs, N. (1990). Structures to resist the effect of accidental explosions. Washington, DC: US Department of the Army and Defense Special Weapons Agency.

Cengel, Y. A., \& Boles, M. A. (2015). Thermodynamics: an engineering approach. New York, NY: McGraw-Hill.

Chen, W. F., \& Mizuno, E. (1990). Nonlinear analysis in soil mechanics: theory and implementation. Amsterdam, North Holland: Elsevier Science Publishers.

Du, Y., Zhang, F., Zhang, A., Ma, L., \& Zheng, J. (2016). Consequences assessment of explosions in pipes using coupled FEM-SPH method. Journal of Loss Prevention in the Process Industries, 43, 549-558.

Gilbert, F. K., \& Kenneth, J. G. (1985). Explosive shocks in air. New York, NY: Springer Science.

Grujicic, M., \& Bell, W. C. (2011). A computational analysis of survivability of a pick-up truck subjected to mine detonation loads. Multidiscipline Modeling in Materials and Structures, 7(4), 386-423.

Grujicic, M., Pandurangan, B., Qiao, R., Cheeseman, B. A., Roy, W. N., Skaggs, R. R., \& Gupta, R. (2008). Parameterization of the porous-material model for sand with different levels of water saturation. Soil Dynamics and Earthquake Engineering, 28(1), 20-35.

Hu, D., Long, T., Liu, C., Yang, G., \& Han, X. (2014). Swelling movement induced by underground explosion of aluminized explosive in multilayered compact material. International Journal of Rock Mechanics and Mining Sciences, 71, 330-339. 
Jing, X. F., Cai, Z. Y., \& Liu, K. H. (2014). Numerical Simulation of Response of Explosion Ground Shock to Buried Gas Pipeline. Applied Mechanics and Materials, 448, 3970-3974.

Johnson, G. R., \& Cook, W. H. (1983). A constitutive model and data for metals subjected to large strains, high strain rates and high temperatures, presented at the 7th International Symposium on Ballistics, The Hague, April 1983. The Hague, South Holland: 7th International Symposium on Ballistics Publishing.

Johnson, G. R., \& Cook, W. H. (1985). Fracture characteristics of three metals subjected to various strains, strain rates, temperatures and pressures. Engineering Fracture Mechanics, 21(1), 31-48.

Johnson, G. R., Hoegfeldt, J. M., Lindholm, U. S., \& Nagy, A. (1983). Response of various metals to large torsional strains over a large range of strain rates-part 1: ductile metals. Journal of Engineering Materials and Technology, 105, 42-47.

Koneshwaran, S., Thambiratnam, D. P., \& Gallage, C. (2015). Blast response of segmented bored tunnel using coupled SPH-FE method. Structures, 2, 58-71.

Laine, L., \& Sandvik, A. (2001). Derivation of mechanical properties for sand. Presented at the 4th Asia-Pacific Conference on shock and impact loads on structures, Singapore, November 2001. Singapore: CI-Premier.

Li, M., Lu, X., Lu, X., \& Ye, L. (2014). Influence of soil-structure interaction on seismic collapse resistance of super-tall buildings. Journal of Rock Mechanics and Geotechnical Engineering, 6(5), 477-485.

Luccioni, B. M., Ambrosini, R. D., Nurick, G., \& Snyman, I. (2009). Craters produced by underground explosions. Computers \& Structures, 87(21), 1366-1373.

Mambou, L. L. N., Ndop, J., \& Ndjaka, J. M. B. (2015). Modeling and numerical analysis of granite rock specimen under mechanical loading and fire. Journal of Rock Mechanics and Geotechnical Engineering, 7(1), 101-108.

Mirzaei, M., Najafi, M., \& Niasari, H. (2015). Experimental and numerical analysis of dynamic rupture of steel pipes under internal high-speed moving pressures. International Journal of Impact Engineering, 85, 27-36.

Mokhtari, M., \& Nia, A. A. (2015). A parametric study on the mechanical performance of buried X65 steel pipelines under subsurface detonation. Archives of Civil and Mechanical Engineering, 15(3), 668-679.

Mokhtari, M., \& Nia, A. A. (2016). The application of CFRP to strengthen buried steel pipelines against subsurface explosion. Soil Dynamics and Earthquake Engineering, 87, 52-62.

Panji, M., Koohsari, H., Adampira, M., Alielahi, H., \& Marnani, J. A. (2016). Stability analysis of shallow tunnels subjected to eccentric loads by a boundary element method. Journal of Rock Mechanics and Geotechnical Engineering, 8(4), 480-488.

Rickman, D. D., \& Murrell, D. W. (2007). Development of an improved methodology for predicting airblast pressure relief on a directly loaded wall. Journal of Pressure Vessel Technology, 129(1), 195-204.

Seidt, J. D., Gilat, A., Klein, J. A., \& Leach, J. R. (2007). High strain rate, high temperature constitutive and failure models for EOD impact scenarios, presented at the SEM Annual Conference \& Exposition on Experimental and Applied Mechanics, Springfield, June 2007. Springfield, Massachusetts: Society for Experimental Mechanics.

Son, J., \& Lee, H. J. (2011). Performance of cable-stayed bridge pylons subjected to blast loading. Engineering Structures, 33(4), 1133-1148.

Steinberg, D. J., Cochran, S. G., \& Guinan, M. W. (1980). A constitutive model for metals applicable at high-strain rate. Journal of Applied Physics, 51(3), 1498-1504.

Tarefder, R. A., Ahmed, M. U., \& Rahman, A. (2016). Effects of cross-anisotropy and stressdependency of pavement layers on pavement responses under dynamic truck loading. Journal of RockMechanics and Geotechnical Engineering, 8(3), 366-377.

Trelat, S., Sochet, I., Autrusson, B., Cheval, K., \& Loiseau, O. (2007). Impact of a shock wave on a structure on explosion at altitude. Journal of Loss Prevention in the Process Industries, 20(4), 509-516.

Wilkening, H., \& Baraldi, D. (2007). CFD modelling of accidental hydrogen release from pipelines. International Journal of Hydrogen Energy, 32(13), 2206-2215. 
Yang, Y., Xie, X., \& Wang, R. (2010). Numerical simulation of dynamic response of operating metro tunnel induced by ground explosion. Journal of Rock Mechanics and Geotechnical Engineering, 2(4), 373-384.

Zhang, B. Y., Li, H. H., \& Wang, W. (2015). Numerical study of dynamic response and failure analysis of spherical storage tanks under external blast loading. Journal of Loss Prevention in the Process Industries, 34, 209-217.

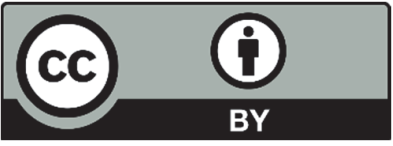

(C) 2017 by the authors; licensee Growing Science, Canada. This is an open access article distributed under the terms and conditions of the Creative Commons Attribution (CC-BY) license (http://creativecommons.org/licenses/by/4.0/). 